\title{
Self-organization of information processing in developing neuronal networks
}

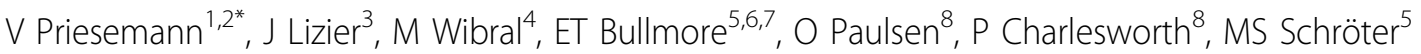 \\ From 24th Annual Computational Neuroscience Meeting: CNS*2015 \\ Prague, Czech Republic. 18-23 July 2015
}

Human brains possess sophisticated information processing capabilities, which rely on the coordinated interplay of billions of neurons. Despite recent advances in characterizing the collective neuronal dynamics, however, it remains a major challenge to understand the principles of how functional neuronal networks develop and maintain these processing capabilities. A popular hypothesis is that neuronal networks self-organize to a critical state [1-3], because in models, criticality maximizes information processing capacities [4-6]. This predicts that biological networks should develop towards a critical state during maturation, and at the same time processing capabilities should increase. We tested this hypothesis using multi-electrode spike recordings in mouse hippocampal and cortical neurons over the first four weeks in vitro. We showed that developing neuronal networks indeed increased their information processing capacities, as quantified by transfer entropy and active information storage [6-8]. The increase in processing capacity was tightly linked to decreasing the distance to criticality (correlation $\mathrm{r}=0.68, \mathrm{p}<10^{-9} ; \mathrm{r}=0.55, \mathrm{p}<10^{-6}$ for transfer and storage, respectively). Thereby our results for the first time demonstrate experimentally that approaching criticality with maturation goes in hand with increasing processing capabilities.

\footnotetext{
Authors' details

'Department of Nonlinear Dynamics, Max Planck Institute for Dynamics and Self-Organization, Göttingen, Germany. ${ }^{2}$ Bernstein Center for Computational Neuroscience, Göttingen, Germany. ${ }^{3}$ School of Civil Engineering, University of Sydney, Sydney, Australia. ${ }^{4}$ MEG Unit, Brain Imaging Center, Goethe

University, Frankfurt am Main, Germany. ${ }^{5}$ Behavioural \& Clinical Neuroscience Institute, Department of Psychiatry, University of Cambridge, Cambridge CB2 3EB, UK. ${ }^{6}$ Cambridgeshire and Peterborough NHS Foundation Trust, Cambridge CB21 5HH, UK. ${ }^{7}$ GlaxoSmithKline, Immuno Psychiatry, Alternative

* Correspondence: viola@nld.ds.mpg.de

'Department of Nonlinear Dynamics, Max Planck Institute for Dynamics and Self-Organization, Göttingen, Germany

Full list of author information is available at the end of the article
}

Discovery and Development, Stevenage SG1 2NY, UK. ${ }^{8}$ Department of Physiology, Development and Neuroscience, University of Cambridge, Physiological Laboratory, Downing Street, Cambridge CB2 3EG, UK.

Published: 18 December 2015

\section{References}

1. Beggs JM, Plenz D: Neuronal avalanches in neocortical circuits. J Neurosci 2003, 23(35):11167-11177.

2. Priesemann V, Valderrama M, Wibral M, Le Van Quyen M: Neuronal avalanches differ from wakefulness to deep sleep-evidence from intracranial depth recordings in humans. PLoS Comput Biol 2013, 9(3): e1002985.

3. Priesemann V, Wibral M, Valderrama M, Proepper R, Le Van Quyen M, Geisel T, Triesch J, Nikolic D, Munk MHJ: Spike avalanches in vivo suggest a driven, slightly subcritical brain state. Front Syst Neurosci 2014, 8:108.

4. Bertschinger $N$, Natschläger $T$ : Real-time computation at the edge of chaos in recurrent neural networks. Neural Comput 2004, 16(7):1413-1436.

5. Boedecker J, Obst O, Lizier JT, Mayer NM, Asada M: Information processing in echo state networks at the edge of chaos. Theory Biosci 2012, 131(3):205-213.

6. Wibral M, Lizier J, Priesemann V: Bits from Brains for Biologically-Inspired Computing. Computational Intelligence 2015, 2:5.

7. Lizier JT, Prokopenko M, Zomaya AY: The Information Dynamics of Phase Transitions in Random Boolean Networks. ALIFE 2008, 374-381.

8. Schreiber T: Measuring Information Transfer. Phys Rev Lett 2000, 85:461-464.

\section{doi:10.1186/1471-2202-16-S1-P221}

Cite this article as: Priesemann et al:: Self-organization of information processing in developing neuronal networks. BMC Neuroscience 2015 16(Suppl 1):P221.

\section{Submit your next manuscript to BioMed Central} and take full advantage of:

- Convenient online submission

- Thorough peer review

- No space constraints or color figure charges

- Immediate publication on acceptance

- Inclusion in PubMed, CAS, Scopus and Google Scholar

- Research which is freely available for redistribution
() Biomed Central
2015 Priesemann et al. This is an Open Access article distributed under the terms of the Creative Commons Attribution License (http://creativecommons.org/licenses/by/4.0), which permits unrestricted use, distribution, and reproduction in any medium, provided the original work is properly cited. The Creative Commons Public Domain Dedication waiver (http://creativecommons.org/ publicdomain/zero/1.0/) applies to the data made available in this article, unless otherwise stated. 